\title{
Implementing the essential medicine concept in the country with the highest GDP per capita in the world
}

A.M. Cheraghali ${ }^{1}$

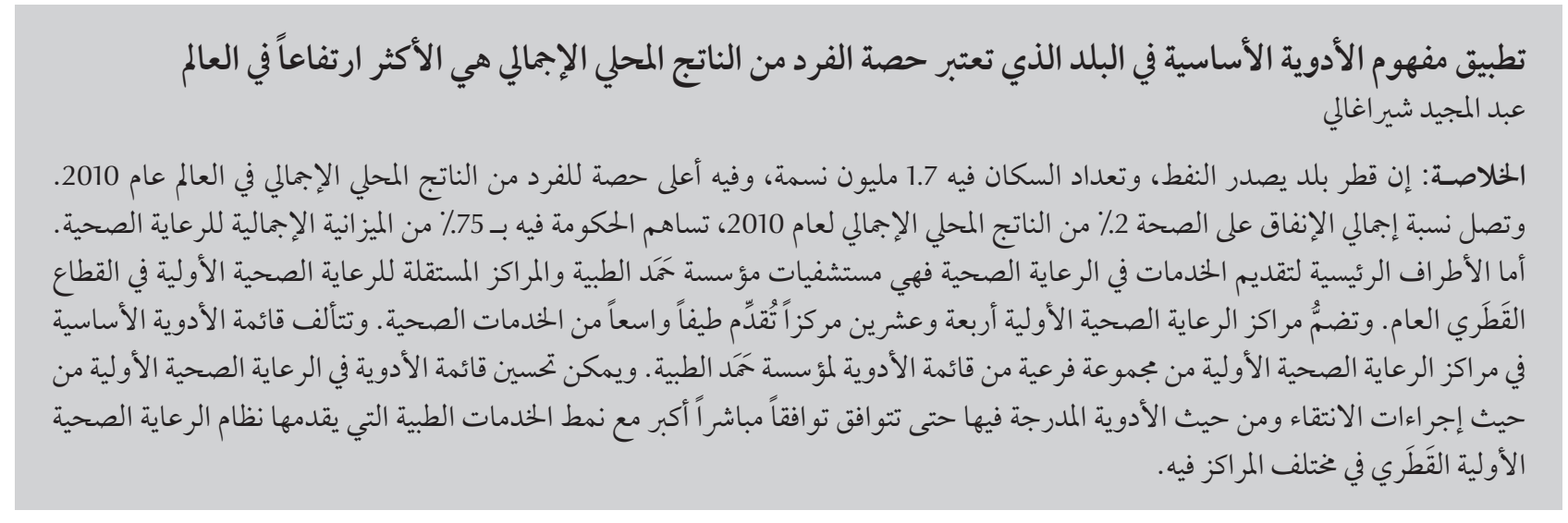

ABSTRACT Qatar, an oil-exporting country with a population of about 1.7 million, achieved the highest gross domestic product (GDP) per capita in the world in 2010. Total health expenditure as a percentage of GDP in 2010 in Qatar was 2.0\%, with the government's share at 75\% of the total health care budget. Hamad Medical Corporation hospitals and the independent public Qatar Primary Health Care (PHC) centres are the main public health care service providers. PHC consists of 24 centres providing a wide range of health services. The PHC medicines list is a subset of the Hamad Medical Corporation medicine list. However, the PHC list of medicines could be improved both in its selection procedures and medicines included to correlate more directly to type of medical services provided by the Qatar PHC system in its different types of centres.

\begin{abstract}
Mise en œuvre du concept des médicaments essentiels dans le pays ayant le PIB par habitant le plus élevé au monde

RÉSUMÉ Le Qatar, pays exportateur de pétrole dont la population s'élève à environ 1,7 million d'habitants, a atteint le produit intérieur brut par habitant le plus élevé au monde en 2010. Dans ce pays, les dépenses de santé totales en pourcentage du produit intérieur brut (PIB) en 2010 étaient de 2,0\% et le gouvernement assumait 75 \% du budget des soins de santé total. Les hôpitaux de la Hamad Medical Corporation ainsi que les centres de soins de santé primaires publics et indépendants du Qatar sont les principaux prestataires de services de soins de santé publics. Ces centres, qui sont au nombre de 24, fournissent un large éventail de services de soins de santé. La liste des médicaments de ces centres de soins de santé primaires représente un sous-ensemble de la liste de médicaments de la Hamad Medical Corporation. Toutefois, la liste des médicaments essentiels des centres de soins de santé primaires pourrait être améliorée à la fois dans les procédures de sélection et le choix des médicaments pour correspondre plus directement au type de services médicaux offerts par le système des centres de soins de santé primaires dans ses différents types de centres.
\end{abstract}




\section{Introduction}

Qatar is a member state of World Health Organization (WHO) Eastern Mediterranean Region (EMR). The economy of the country is mainly dependent on oil and gas, which makes up about $56 \%$ of its total gross domestic product (GDP) in $2010[1,2]$. Qatar has experienced a significant increase in its population over the last 10 years. The population of Qatar has increased by $176 \%$ between 2000 and 2010 (from 616000 to 1700 000) [3]. The high demand of oil and gas over the past decades and the corresponding cash revenues generated have resulted in a demand for labour, especially young expatriate males. Therefore the majority of people residing in Qatar are non-Qatari expatriates. The expatriate labourers constitute about $54 \%$ of the population [3]. Due to constant increases in the price of oil and gas, the GDP per capita in Qatar in 2010 was about US $\$ 88559$, the highest in the world. Total health expenditure as a percentage of GDP in 2010 in Qatar was $2.0 \%$. The Qatar government's share of the health care budget in 2010 was $75 \%$. However, private health services have also grown at a fast growth pace in recent years in Qatar. Currently Hamad Medical Corporation (HMC) hospitals and the independent public Qatar Primary Health Care (PHC) centres are the main public health care service providers.

According to report published by the policy affairs directorate of the Supreme Council of Health of Qatar on June 2011 health care and public health services in Qatar are comparable with those of developed countries and have steadily improved over the past 30 years [4]. The crude death rate has declined from 2.5 per 1000 inhabitants in 1981 to 1.9 in 2005. Infant mortality has halved from 17.0 per 1000 live births in 1981 to 8.2 in 2006.

The Supreme Council of Health as the steward of the health of Qatar's people was established in 2009 and given the responsibility to guide reform in Qatar in order to establish "one of the world's most admired and renowned health systems" [4]. The Council's role is to create a clear vision for the nation's health direction, set goals and objectives for the country, design policies to achieve the vision, regulate the medical landscape, protect the public's health, set the health research agenda and monitor and evaluate progress towards achieving those objectives.

The Council does not provide clinical services. Instead its goal is to vest responsibility for care in the hands of public institutions such as HMC, Qatar $\mathrm{PHC}$ and the private sector while regulating, monitoring and evaluating this care against agreed-upon outcomes to ensure that acceptable quality of care is provided. HMC, which was established in 1979, provides secondary and tertiary health care services through its hospitals [5].

\section{Qatar Primary Health Care}

The establishment of Qatar PHC in Qatar goes back to as early as 1954 in an effort to cope with the increasing population after oil production accelerated. In 1978 the Ministry of Health developed a comprehensive scheme for a PHC system. The aim was to raise the health standard of the community as a first line of health defence and also to provide support to the hospitals. Qatar PHC consists of 24 centres (11 of which are in Doha) and provides general and clinical services plus emergency services. The range and type of PHC services provided in Qatar are more extensive than the services usually provided by PHC centres in other countries [6]. PHC centres provide health services including diagnosis and treatment of disease, basic dentistry services, pregnancy care, vaccination, health education, pharmacy and drug prescription services, laboratory analyses, vital statistics, social work, home visits and referral of patients for secondary care. Patients who need inpatient services and/or hospitalization or specialty treatment are referred to HMC hospitals. Although Qatar PHC centres provide different level of medical services in different centres (mainly could be categorized in 2 different levels), there is obviously some degree of overlap in medical services provided in Qatar $\mathrm{PHC}$ and HMC centres.

\section{Current list of medicines}

Registration of medicines in Qatar is based on safety, quality and efficacy. Marketing authorization is handled by the department of registration in the $\mathrm{Su}$ preme Council of Health. Both HMC and $\mathrm{PHC}$ have their own medicine lists which have been selected by their own pharmacy and therapeutic committees. The HMC medicine list contains more than 4000 medicines [5]. The HMC pharmacy and therapeutic committee has more members (12 members) than the Qatar PHC committee (6 members). The PHC medicines list (about 700 ) is a subset of the HMC medicine list.

The HMC pharmacy and therapeutic committee carries out the following functions:

- Develops and maintains a basic drug list or formulary of accepted drugs for use in the hospital.

- Serves as an advisory body to the medical staff and hospital administration in all matters pertaining to the use of drugs.

- Establishes formulary policies and regulations and ensures strict adherence to them.

- Carries out regular review and updating of these policies.

- Reviews requests for addition/deletion of drugs to the list.

- Establishes subcommittees for problem related to the different groups of drugs. 
- Initiates a system to monitor medication errors.

A PHC list of medicines has been developed by the Qatar PHC therapeutic committee. The committee consists of 2 pharmacists and 4 physicians from different disciplines. The committee meets regularly and deals with different aspects of medicines and pharmacy practices in $\mathrm{PHC}$ centres including the medicines list, policy-making, medicine errors and follow ups of prescribers. In addition to the medicines on the list, physicians practising in $\mathrm{PHC}$ centres can request out-of-list medicines for specific patients. There are also some therapeutic guidelines developed by the pharmacy and therapeutic committee, e.g. for management of type 2 diabetes. The department of pharmacy service of PHC provide monthly reports of the total medicines used in different departments and PHC centres. As an example in July 2011 this department filled 175951 prescriptions in $24 \mathrm{PHC}$ centres. Based on an internal report the PHC service pays on average about US\$ 3.5 million for medicines in its centres. However, the total expenditure on drugs and pharmaceuticals of the public sector in Qatar in 2010 was US\$ 143 million [4].

\section{Future activities in Qatar PHC}

Qatar PHC already uses a fairly comprehensive medicine list which includes more than 700 medications. This list which in fact is part of a larger list prepared by HMC was selected by the PHC therapeutic committee. However, the PHC list of medicines could be improved both in its selection procedures and medicines included. The list could be rearranged in a more scientific presentation and correlate more directly to the range and type of medical services provided by $\mathrm{PHC}$ in its different types of centres. A small reorganization of current procedures in Qatar PHC could result in implementation of the essential medicines concept in Qatar PHC system. These are some of the proposed modifications to upgrade Qatar national medicine list.

- Establishment of an expert committee for developing/revising the Qatar PHC medicine list. Such a committee should follow the structure and working procedures recommended by WHO guidelines [7]. The pharmacy and therapeutic committee of the PHC service, with some minor modification in its organization and membership, could act as the PHC committee for developing/revising the medicines list. After establishing the committee, the content of the current PHC medicines list could be revised based on scientific evidence and the range of services provided by PHC centres in an agreed time frame. At this stage the committee should pay special attention to the needs of children for appropriate medicines and/or dosage forms [7].

- The new list should be categorized based on types and range of the medical services which each level of PHC centre offers to patients. The committee should decide which medicines on the list could be prescribed in which PHC centres. The new Qatar PHC list of medicine should then be implemented in PHC centres.

- Based on the author's observations in some PHC centres it was clear that Qatar national health officials should pay more attention to promoting appropriate use of medicines. Due to inappropriate use of medicines in some occasions especially high number of items per prescription it is recommended that an orchestrated programme in promoting rational prescription of medicines should also be a priority for the Qatar national health system. Such a programme should include all 3 components of training, supervision and monitoring of prescription patterns in Qatar PHC centres. Currently there are high numbers of non-Qatari physicians practising in Qatar health care centres and in fact most of physicians in these centres are non-Qatari. Therefore, based on possible different educational background it would be worthwhile to compare the prescribing pattern of medicine in these 2 groups of physicians (Qatari and non-Qatari).

- In addition to revising the current medicines list the establishment of a national pharmacovigilance programme could greatly improve safety of the medicines use. Therefore, the establishment of a nationwide pharmacovigilance programme should be as one of the priority of Qatar national health system.

\section{References}

1. World economic book database. International Monetary Fund [online database] (http://www.imf.org/external/pubs/ft/ weo/2011/update/02/index.htm, accessed 12 November 2012).

2. Census 2010. Qatar Statistics Authority Fund [online database] (http://www.qsa.gov.qa/QatarCensus/Default.aspx, accessed 23 September 2012).

3. Country profiles: Qatar. World Health Organization [online database] (http://www.who.int/countries/qat/en/, accessed 23 September 2012).

4. Qatar national health accounts: 1st report years 2009 and 2010. A baseline analysis of health expenditure and utiliza- tion, June 2011. Qatar, Supreme Council of Health State of Qatar, Policy Affairs Directorate, 2011 (www.sch.gov.qa/ sch/UserFiles/File/QHA_2011_eng(1).pdf, accessed 23 September 2012).

5. Hamad Medial Corporation [website] (http://www.Hmc.org. qa, accessed 23 September 2012).

6. The world health report 2008: primary health care (now more than ever). Geneva, World Health Organization, 2008.

7. Summary of the report of the 18th meeting of the WHO Expert Committee on the Selection and Use of Essential Medicines. Geneva, World Health Organization, 2011. 